International

Medical Society

http://imedicalsociety.org

\title{
of the Common Facial Vein. A Morphologycal Study
}

\author{
Sergio Ivan Granados-Torres ${ }^{1}$, Humberto Ferreira-Arquez ${ }^{2}$
}

\section{Abstract}

Background: Anatomical knowledge of the facial vasculature is crucial not only for anatomists but also for oral and maxillofacial surgery, plastic surgeon, otorhinolaryngologists. Access pathways, pedicled and free flap transfer, and explantation and transplantation of total faces are based on the proper assessment and use of the facial veins and arteries. The anatomical variations reported in the present study confirms the need for preoperative vascular imaging for sure good venous outflow for the free flap survival.

Aims: The aim of the present study was to describe a rare anatomical variation of the common facial vein which not been previously described.

Methods and Findings: Head and neck region were carefully dissected as per standard dissection procedure, studied serially during the years 2013-2017 in 15 males and 2 females, i.e. 34 sides, embalmed adults cadavers with different age group, in the laboratory of Morphology of the University of Pamplona. In 33 sides (97\%) of the cases the anterior facial vein (FV) terminated into the internal jugular vein via the common facial vein (CFV) as per standard anatomic description. The right common facial vein in one side (3\%) was found to drain into the contralateral internal thoracic vein and contralateral pericardiophrenic vein. Remarkable communications with the external jugular vein, the internal jugular vein, the anterior jugular vein, and left brachiocephalic vein. The length of the right common facial vein from the level of its formation till its termination in the contralateral pericardiophrenic and internal thoracic vein was about $22.75 \mathrm{~cm}$. The venous drainage pattern on the left side of the face was found to be normal.
1 Medicine student sixth Semester, University of Pamplona, Norte de Santander, Colombia, South America

2 Professor Human Morphology, Medicine Program, University of Pamplona, Morphology Laboratory Coordinator, University of Pamplona.

\section{Contact information:}

Ivan Granados-Torres.

Address: University Campus, Kilometer 1. Via Bucaramanga. Norte de Santander, Colombia. Suramérica, Pamplona Zip code: 543050

Tel: 573176222213

ĐSergio.ivan98@outlook.com 
Conclusion: The existence of this anatomical variation among others supposes a double edge sword in the medical practice with its own opportunities and risks, especially in the surgical treatment; therefore, we need to study with more strictness these possibilities with the aim of facilitate this practices, and improve the life quality of our patients.

\section{Keywords}

Anatomical Variation; Common Facial Vein; External Jugular Vein; Internal Jugular Vein; Brachiocephalic Vein; Anterior Jugular Vein; Pericardiophrenic Vein; Internal Thoracic Vein.

\section{Introduction}

If we do a quick revision about the anatomical variations that have been found in the human body, it is not weird to see that the veins of the head and the neck make various appearances in leading roles, therefore we can infer that these blood vessels are very prone to present a wide range of variations. Commonly, the anterior facial vein start from the confluence of the supratrochlear and the supra-orbital veins in the middle third of the face. The superficial temporal vein unites with the maxillary vein to form the retromandibular vein. The retromandibular vein divides into the anterior and the posterior divisions within the substance of the parotid gland. In the normal anatomy this anterior division joins to the anterior facial vein giving the common facial vein, which drains into the internal jugular vein. The posterior division, on the other side, joins with the posterior auricular vein, continuing as the external jugular vein which drains into the subclavian vein $[1,2]$. The anterior jugular veins usually exist as two parallel vessels which drains into the subclavian vein or into the external jugular vein through a submandibular venous arch [3], finally we need to describe a part of the ve- nous drainage of the thorax, specifically, we have to mention the left pericardiophrenic vein, which, as its name indicates, is formed from the venous branches draining the diaphragm's superior border or thoracic diaphragm and the pericardium; the left pericardiophrenic vein drains normally into the floor of the left brachiocephalic vein [4], for its part the internal thoracic veins (internal mammary veins) are venae comitantes to the inferior half of the internal thoracic artery. They have several valves. Near the third costal cartilages, the veins unite and ascend medially to the artery to end in their appropriate brachiocephalic vein. Tributaries correspond to artery branches $[5,6]$.

The veins of head and neck have a very relevant importance in a whole of medical and surgical procedures, for example, these veins can be used as patches for carotid endarterectomy and for oral reconstruction surgeries being really remarkably in those cases the need of a vast vascularization [7]. Today's diagnostic, monitoring and therapeutic procedures are needed in diverse groups of patients. In the case of monitoring this is very obvious in the patients who are in the intensive care units (ICU) also known as critical care units (CCU), who are in a very precarious situation which needs a constant 
observation, in order to have any information possible that could to ease a convenient evolution. In the therapeutic side it is enough to see how many drugs need a parenteral administration and specifically an intravenous administration, being of vital importance to our professionals of health and specially to the radiologist, surgeons and physicians the clear knowledge of the human anatomy and a general knowledge about the possible variations that could be present, aiming to avoid any complications that could be presented [7], in this therapeutic side we can peculiarly mention that superficial veins of the head and neck are utilized for central venous cannulation, oral reconstruction and parenteral nutrition in debilitated patients [8]. And in what concerns to the diagnostic it is very interesting to see that clinical and sonological examination of these veins may provide clues toward underlying cardiac pathology [9].

As a clinical inference the external veins of the head and neck are of particular interest in the use as patches for surgery to remove plaque buildup in the carotid arteries; for oral reconstruction surgeries, where the creation of a vascular supply by anastomosis is crucial and in this case is recognized the participation of the facial vein [1], in the particular case of aesthetic procedures and plastic surgery a relevant complication to consider besides the insufficient arterial irrigation is the partial necrosis of skin flaps due to congestions who derives from a poor venous drainage making the cardiovascular anatomy of the intervention site an important factor to consider [10]. The aim of the present study was to describe an anatomical variation who hasn't been reported before according to our bibliographic revision, who involves a vast number of anastomosis (transverse venous connections) of the right common facial vein with other neighbor veins, an a very rare draining of this in the contralateral brachiocephalic vein, contralateral pericardiophrenic vein and in the contralateral internal thoracic vein, such a rare variation suppo- ses both, an interesting opportunity concerning to some procedures, and a really dangerous risk in those procedures.

\section{Methods}

This work was previously approved by the Ethics Committee in Research and Environmental Impact of the University of Pamplona, conformed by resolution 030 of January 16 of 2014 and Resolution No. 008430 of 1993 of October 4 of the Ministry of Health of Republic of Colombia which regulates the scientific, technical and administrative norms for health research. This descriptive cross-over study was designed to identify the morphologic features and anatomical variations in the termination of the facial vein. Head and neck region were carefully dissected as per standard dissection procedure, studied serially during the years 2013-2017 in 15 male and 2 females, i.e. 34 sides, embalmed adults cadavers with different age group, in the laboratory of Morphology of the University of Pamplona. None of the cadavers utilized for the present study had previous facial surgery or any relevant disease affecting the integrity of the facial anatomy. The cadavers had no trace of scars, adhesions or signs of trauma. This study was carried out by routine dissection classes for undergraduate medical students. Topographic details of the variations were examined, recorded and photographed. Measurements were taken with assistance of a sliding Vernier caliper with an accuracy of $0.01 \mathrm{~mm}$ during the course of the anatomical dissection.

\section{Results}

In 33 sides (97\%) of the cases the anterior facial vein (FV) terminated into the internal jugular vein via the common facial vein (CFV) as per standard anatomic description. In all specimens the external jugular vein is formed by union of posterior division of retromandibular vein and posterior auricular vein. 
The lingual vein drain into the internal jugular vein.

In the right side (3\%) the common facial vein was formed by union of the anterior division of retromandibular vein (RMV-AD); the inferior masseteric vein (IMV); the submental vein (SMV); the external palatine vein (EPV); the facial vein (FV). The common facial vein present anastomosis (transverse venous connections) with internal jugular vein (in the upper third of the neck) at $34.5 \mathrm{~mm}$ below the angle of the mandible and external jugular vein (in the middle third of the neck) at $69 \mathrm{~mm}$ below the angle of the mandible. The diameters of the transverse venous connections were of 5.53 and $5.95 \mathrm{~mm}$, respectively. Figure 1.

At level of the inferior third of the neck, the right anterior jugular vein drain into common facial vein on its anterior aspect $(33.8 \mathrm{~mm}$ above the right sternoclavicular joint). There was no jugular venous arch in the suprasternal space. On the posterior aspect of the common facial vein $(10 \mathrm{~mm}$ above the right sternoclavicular joint) is observed a communicating branch (of $56.5 \mathrm{~mm}$ of length and $6.35 \mathrm{~mm}$ of diameter) united with the external jugular vein to form a common venous trunk which terminated into subclavian vein. Figure 2.

The right common facial vein (CFV) descended obliquely downwards and forward superficial to the sternocleidomastoid, appeared in the suprasternal space. CFV is oriented laterally obliquely, deep to the brachiocephalic artery trunk, but superficial to the left brachiocephalic vein. CFV anastomosed with left brachiocephalic vein and terminating into contralateral pericardiophrenic vein and into contralateral internal thoracic vein. Figure $\mathbf{3}$. The length of the right common facial vein from the level of its formation till its termination in the contralateral pericardiophrenic and internal thoracic vein was about $22.75 \mathrm{cms}$. The venous drainage pattern on the left side of the face was found to be normal.
Figure 1: Lateral view of neck and angle of the mandible. Right site. External jugular vein.

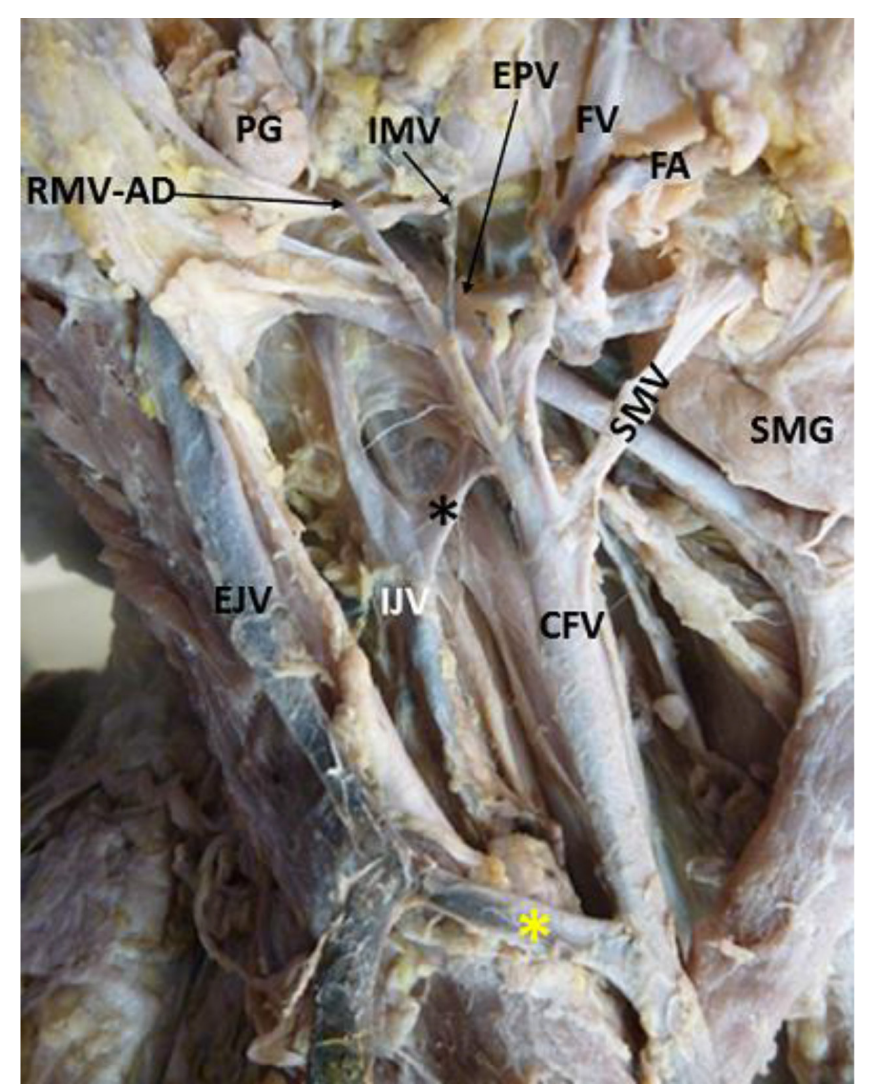

EJV; facial vein: FV; facial artery: FA; internal jugular vein: IJV; retromandibular vein- anterior division: RMV-AD; parotid gland: PG; submandibular gland: SMG; inferior masseteric vein: IMV; submental vein: SMV; external palatine vein: EPV; common facial vein: CFV; black asterisk: anastomosis between internal jugular vein and common facial vein; yellow asterisk: anastomosis between external jugular vein and common facial vein

\section{Discussion}

During embryonic period, superficial head and neck veins develop from superficial capillary plexuses which will later form primary head veins. Larger veins are formed by the enlargement of individual capillaries, confluence of adjacent Ones and regression of some from where the flow has been diverted [11]. The ventral pharyngeal vein (VPV) is the first one identified in face and neck region. VPV develops within the mesenchyme of first branchial arch and joins with the cranial part of primary head vein. Maxillary vein develops within the maxillary 
Figure 2: A) Anterior view of neck. Anterior jugular vein.

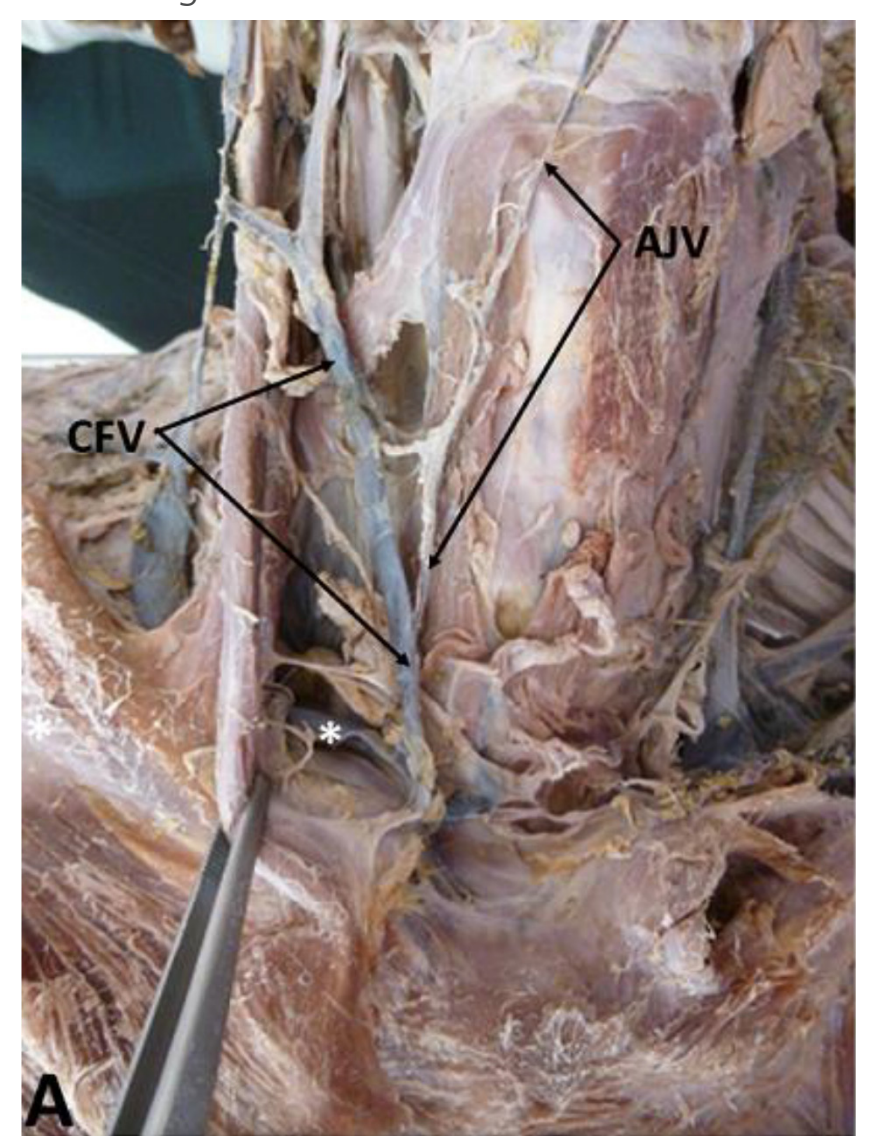

AJV; common facial vein: CFV; white asterisk: communicating branch between common facial vein and external jugular vein
Figure 2: B) Common facial vein.

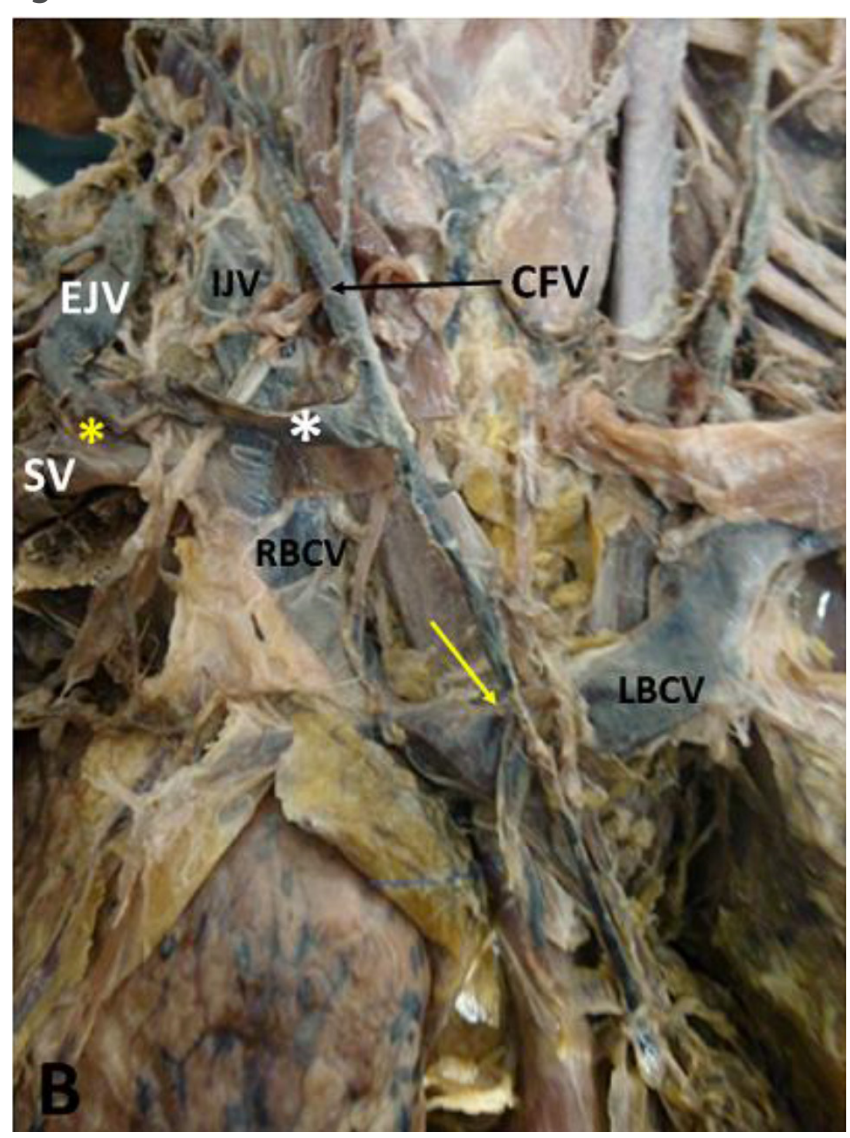

CFV; subclavian vein: SV; left brachiocephalic vein: LBCV; internal jugular vein: IJV; externa jugular vein: EJV; right brachiocephalic vein: $\mathrm{RBCV}$; yellow arrow: anastomosis between left brachiocephalic vein and common facial vein; white asterisk: communicating branch between common facial vein and external jugular vein; yellow asterisk: common venous trunk between EJV and CFV.
Figure 3: Anterior view of neck and thorax. Right lung.

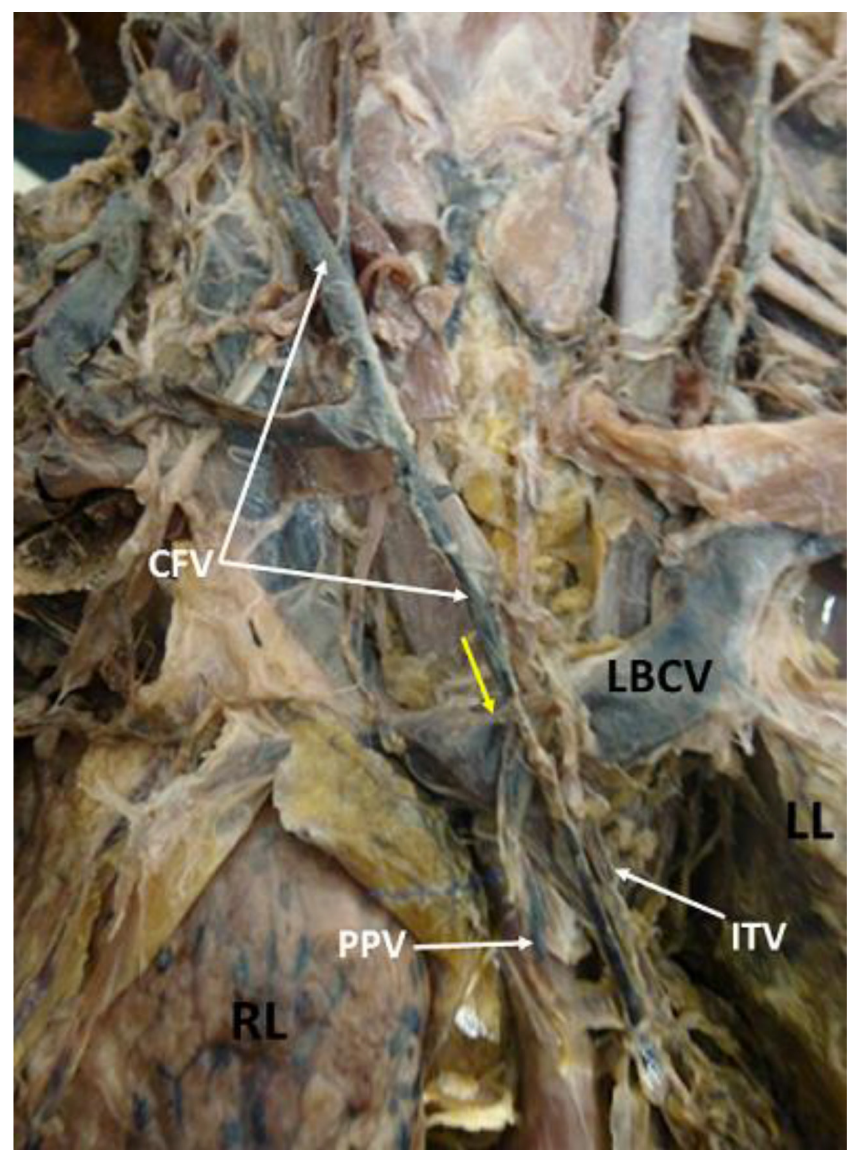

RL; left lung: LL; common facial vein: CFV; pericardiophrenic vein: PPV; internal thoracic vein: ITV; yellow arrow: anastomosis between left brachiocephalic vein and common facial vein. 
Figure 4: Schematic representation of the anomalous venous drainage which have been seen.

A. Lateral view of the neck and the angle of the mandible. Right site. External Jugular Vein.

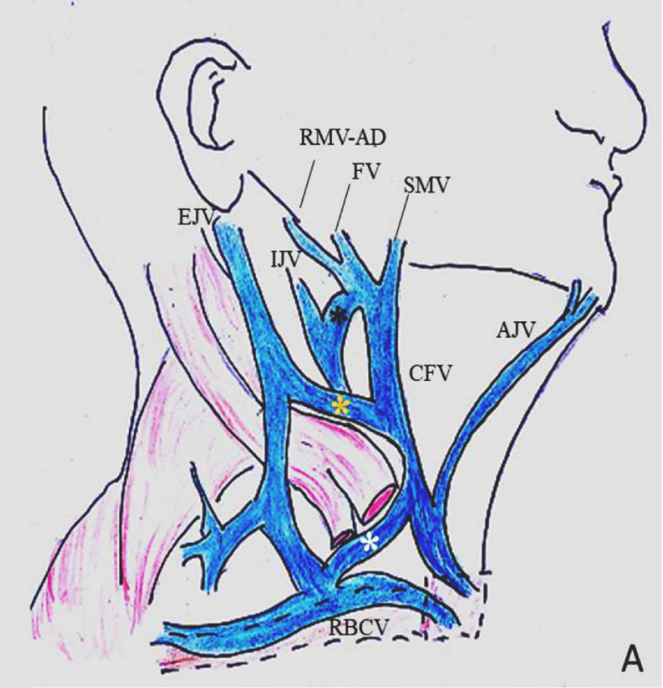

EJV; retromandibular vein- anterior division: RMV-AD; Facial Vein: FV; Submental Vein: SMV; common facial vein: CFV; Anterior Jugular Vein: AJV; black asterisk: anastomosis between internal jugular vein and common facial vein; yellow asterisk: anastomosis between external jugular vein and common facial vein; white asterisk: communicating branch between common facial vein and external jugular vein; right brachiocephalic vein: RBCV.

process of first branchial arch. The venous plexus around developing clavicle along with the veins of first branchial arch which elongates the terminal part of VPV is shifted toward cephalad part of precardinal vein, which later develops in internal jugular vein (IJV) [12]. Frontonasal process and maxillary process join and within its mesoderm linguofacial vein develops and join with VPV. The primitive maxillary vein anastomoses with linguofacial vein to form anterior facial vein. Retromandibular vein develops within the mesenchyme of temporal region and opens into linguofacial vein to form common facial vein (CFV). CFV ultimately drains into (IJV). IJV develops from caudal part of anterior cardinal vein. EJV develops from venous plexus in the neck region connecting caudally with cephalic vein and cranially with retromandibular vein (RMV) and anterior facial vein at 22 $\mathrm{mm}$ stage of embryo [13]. The cephalic vein forms a venous ring around clavicle from which it is connec-
B. Anterior view of neck and thorax. Right internal jugular vein: RIJV; left internal jugular vein.

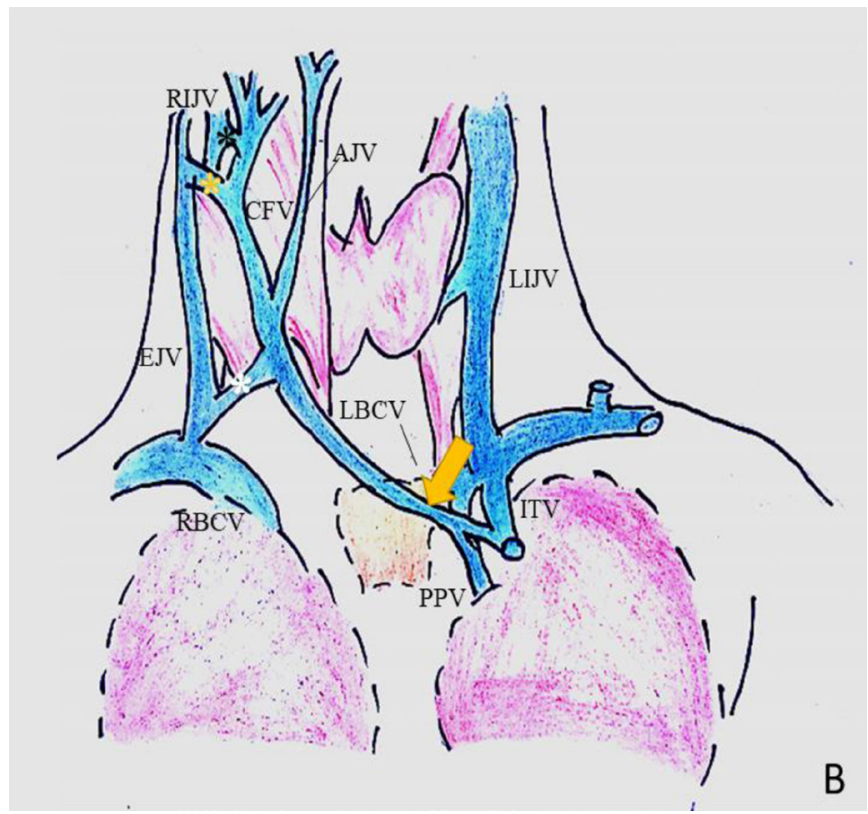

LIJV; left brachiocephalic vein: LBCV; yellow arrow: common facial vein anastomosed with contralateral brachiocephalic vein and terminating into contralateral pericardiophrenic vein and into contralateral internal thoracic vein. ted to the caudal part of precardinal vein. The deep segment of this venous ring form subclavian vein. The part of cephalic vein which is ventral and superficial to the cephalic (Jugulo cephalic part) often dwindles and is lost [14]. The cephalic vein directly opens into axillary vein below the clavicle and external jugular vein (EJV) opens into subclavian vein [15].

The complex embryological development of the vascular system often results in a myriad of clinically relevant anomalies. A variation in the drainage pattern of the veins of the face has been observed in the past. The standard anatomical description of the veins of the face is of superficial temporal vein uniting with maxillary vein within the substance of the parotid gland to form retromandibular vein. The retromandibular vein divides into anterior and posterior divisions before emerging out from the apex of the parotid gland. The anterior branch joins with the facial vein slightly inferior and anterior to the 
angle of mandible to form common facial [16-17]. In the present study, the common facial vein (CFV) was formed by union of the anterior division of retromandibular vein (RMV-AD); the inferior masseteric vein (IMV); the submental vein (SMV); the external palatine vein (EPV); the facial vein (FV). The common facial vein present anastomosis (transverse venous connections) with internal jugular vein (in the upper third of the neck) at $34.5 \mathrm{~mm}$ below the angle of the mandible and external jugular vein (in the middle third of the neck) at $69 \mathrm{~mm}$ below the angle of the mandible. The diameters of the transverse venous connections were of 5.53 and 5.95 $\mathrm{mm}$, respectively.

The CFV crosses the base of mandible, inferior surface of submandibular gland and drain into internal jugular vein. Different patterns of variations in the venous drainage have been observed in the past. A case of FV uniting with the RMV at a higher level in the right parotid gland was observed by Kopuz C et al, [18]. FV draining into the superficial temporal vein, with an undivided RMV was also reported [19]. CFV draining into EJV, an incidence of $5 \%$ was noted in the study done by Choudhry R et al, [20]. In another study conducted by Gupta $\vee$ et al, [21], the incidence of this particular variation was $9 \%$. Pai et al, [22] reported an incidence of $7.7 \%$, is at par with the reported incidence which ranges between $5-9 \%[20,21]$. A unilateral termination of the common facial vein into the subclavian vein on the left side has been reported earlier [16]. Siddaraju SK, reported common facial vein dividing and draining in to external as well as internal jugular veins. [23]. Pikkieff et al, noticed facial vein ending as external jugular vein [24]. Bertha A and Suganthy Rabi [17] found in three specimens, the common facial vein opened into the external jugular vein. In one specimen, on the right side, the common facial vein ran separately for almost the whole length of the neck and opened into the external jugular vein. In other two cadavers, the left common facial vein drained into the external jugular vein, while the right vein drained into the internal jugular vein.
The anterior jugular vein is formed in the hyoid region by the confluence of the superficial submandibular veins and extends vertically downwards, left and right of the midline of the anterior cervical triangle, along the anterior border of the sternocleidomastoid muscle. Nearby the jugular notch of the sternum it passes between the sternocleidomastoid muscle and the infrahyoid muscles. In size it is usually inverse to the external jugular vein $[25,26]$. Finally it drains into the subclavian (54\%) or into the external jugular vein (46\%) [27].The two anterior jugular veins above the jugular notch of the sternum communicate each other by a transverse vein named jugular arch. Regarding the anterior jugular vein variations, it is possible instead of the two anterior jugular veins to be only a single one, localized in the midline of the anterior cervical region called median cervical vein [25-28]. Also it is likely that the upper main part of these veins could be replaced by a grid of venules that drain into the jugular arch [25]. Nayak reported multiple variations of the left jugular veins. The facial vein continued down as anterior jugular vein which was of the same size as the internal jugular vein and drained into the subclavian vein deep to the sternocleidomastoid muscle. In addition the anterior jugular vein had a large communicating branch with the anterior division of the internal jugular vein [29]. Fabian et al. reported an anomaly of the jugular veins system bilaterally, with the right anterior jugular vein draining into the confluence of internal jugular and subclavian vein and with the left anterior jugular vein draining into the terminal portion of the internal jugular vein. The right external and anterior jugular veins were considerably small with the external jugular vein being smaller than the anterior [30]. Maskey et al., described the formation of a common venous channel between internal jugular and anterior jugular vein where the facial, the lingual and the submental vein drained [31, 32]. In the present study at level of the inferior third of the neck, the right anterior jugular vein drain into common facial vein on its anterior aspect $(33.8 \mathrm{~mm}$ 
above the right sternoclavicular joint). There was no jugular venous arch in the suprasternal space. On the posterior aspect of the common facial vein (10 $\mathrm{mm}$ above the right sternoclavicular joint) is observed a communicating branch (of $56.5 \mathrm{~mm}$ of length and $6.35 \mathrm{~mm}$ of diameter) united with the external jugular vein to form a common venous trunk which terminated into subclavian vein. The right common facial vein (CFV) descended obliquely downwards and forward, superficial to the sternocleidomastoid, appeared in the suprasternal space. CFV is oriented laterally obliquely, deep to the brachiocephalic artery trunk, but superficial to the left brachiocephalic vein. CFV anastomosed with left brachiocephalic vein and terminating into contralateral pericardiophrenic vein and into contralateral internal thoracic vein.

The case presented in the present study is considered it as a rare variation has not been previously described. It is the first case reported so far in the available scientific literature.

\section{Clinical Importance}

Standard anatomy textbooks describe the internal thoracic veins (ITVs) as the principal veins on the internal surface of the thorax, accompanying the internal thoracic arteries (ITAs). More specifically, these veins are the venae commitantes to the inferior half of ITAs, corresponding to the superior epigastric veins that mainly receive the anterior intercostal veins. At the point of the manubriosternal joint right internal thoracic vein (RITV) and left internal thoracic vein (LITV) form a common trunk that ascends and joins the right and left brachiocephalic veins respectively $[33,34]$. According to Romanes, the number of RITVs or LITVs could vary from one to two, but these veins will typically unite at the third costal cartilage medial to ITA [35]. The ITVs represent an important and, at times, superior, alternative to other recipient vessels of the region, especially in delayed reconstruction after mastectomy [36]. The importance of such knowledge lies in the fact that the use of ITVs in breast reconstruction has numerous advantages. The ITVs are better than the thoracodorsal vessels with regard to flap positioning, as well as positioning for the vascular anastomoses. The field of dissection is not violated and there is no perivascular scarring in the delayed reconstruction scenario [37]. Although ITAs have been investigated anatomically [38-40] because of their frequent use in cardiac surgery [41-43] or for diagnosis in breast cancer lymphadenopathy [4447], detailed anatomical descriptions of ITVs are still rare [34-48].

The pericardiophrenic vein is a vessel that runs along with the pericardiophrenic artery and phrenic nerve between the pericardial pleura and the pericardium bilaterally. Superiorly, the left pericardiophrenic vein, located on the lateral border of the heart, joins the left internal thoracic vein before draining into the left brachiocephalic vein. Inferiorly, its branches form veno-venous collaterals with the left gastric vein (subdiaphragmatically) and the inferior vena cava (IVC) [48]. The pericardiophrenic vein has been previously described in association with iatrogenic complications, including insertion of central venous catheters and Swan-Ganz catheters [50-52]. Furthermore, the pericardiophrenic vein has also been described in portal hypertension as a collateral pathway draining the left gastric vein $[53,54]$.

Deviation from the normal pattern in the vascular system is a common feature, and it is more common in the veins than in the arteries. Detailed knowledge of normal course, termination and variation of blood vessels is important to avoid complication in surgeries and to prevent undue blood loss. Common facial vein terminating into external jugular vein may give false record of central venous pressure. Complication may occur during central venous catheterization because of such variation. The knowledge of the variations of the superficial veins of the neck the effective utilization of these veins for grafting in endarterectomies [55]. The common 
facial vein has been used as a patch material for carotid angioplasty, as it is almost always available at the carotid exposure site [17]. It can be harvested by the same incision by a simple technique and at no extra operating time $[56,57]$. According to Siddaraju KS, external jugular vein may give diagnostic signs of heart failure. Techniques of central venous catheterization are now of great clinical importance both to measure central venous pressure (CVP), for practical purpose the pressure within the right atrium, and also to allow rapid blood replacement and long term intravenous feeding by means of glucose, amino acids and fats [23, 58-60].

The Jugular venous arch (JVA) is an infrequently found transverse connecting trunk extending across the midline between the two anterior jugular veins (AJV) of either side and lying in the suprasternal space between superficial and pretracheal layers of the cervical fascia [61]. The JVA serves as a natural crossover collateral and may become prominent in cases of deep venous outflow obstruction. It is the midline part of the anterior jugular venous system (AJVS), typically in U-shape or V-shape configuration. Apart from textbooks of surgery in the context of, for example, thyroid surgery or tracheostomy, it is mentioned in the literature mostly in relation to malposition of central vein catheters or unintended crossover placement of central lines $[62,63]$.

The AJVS is an important collateral venous network across the midline of the superoanterior aspect of the thorax and, if fully developed, is composed of three segments: the JVA as the transverse midline segment [64] and the two as infrequently found horizontal lateral segments connecting the JVA to the subclavian vein (SV), external jugular vein (EJV), or more rarely internal jugular vein (IJV). It is worth emphasizing that "anterior jugular venous system" is to be understood as a clinical and not as an anatomical term. In the anatomical images or the textbooks of anatomy, the horizontal lateral segment of the AJVS often is unmarked or rather regarded as the termination of the AJV. Correspon- ding to its variability, the AJVS shows a wide array of formation, course, communication, and termination [65]. Schummer et al. [66] stated that correct placement of central venous catheters through the AJVS may be possible.

\section{Conclusion}

We have found not only a rare but also a really important anatomical variation in the venous drainage pattern of the face and neck which is involving even the venous drainage of the contralateral side of the thorax, this anatomical variation supposes a therapeutic opportunity in the case of plastic surgery procedures such as the use of skin flaps which can be favored by the presence of an extensive venous drainage like the one that we have reported here. In the other hand we need to remark that this anomalous drainage also supposes a important risk to be taken into account in the performing of some diagnostic procedures in one side and face, neck, and even thorax surgeries on the other side, who could have very compromising iatrogenic complications like unnecessary hemorrhages. As we can see it is really important to keep forward with anatomical studies to discover such variations, and it would be ideal to perform an exploration of the irrigation and drainage before a surgical intervention to avoid a considerable number of complications.

\section{Acknowledgement}

The author thanked to the University of Pamplona for research support and/or financial support; at National Institute of Legal Medicine and Forensics Sciences and Erasmo Meoz University Hospital in Cucuta, North of Santander, Colombia for the donation of cadavers identified, unclaimed by any family, or persons responsible for their care, process subject to compliance with the legal regulations in the Republic of Colombia. 


\section{Competing interests}

None

\section{Fundings}

This study was supported by University of Pamplona.

\section{Institution responsible for research support and/or financial support}

University of Pamplona.

\section{References}

1. Silva M, Henriques J, Silva J, Camargos V, Moreira P. Venous arrangement of the head and neck in humans-anatomic variability and its clinical inferences. J. Morphol. Sci. 2016; 33(1):22-8. Available from: http://jms.org.br/PDF/v33n1a06.pdf

2. Ferreira-Arquez $\mathrm{H}$. Facial vein variation: A cadaveric study. International Archives of Medicine, 11. DOI: http://doi. org/10.3823/2547.

3. Tubbs RS, Watanabe K. Veins of the Neck. In Tubbs RS, Loukas M, Shoja MM. Bergman's comprehensive encyclopedia of human anatomic variation: John Wiley \& Sons. 2016; 821-5. Available from: http://onlinelibrary.wiley.com/ doi/10.1002/9781118430309.ch63/summary

4. Krishnan A, Cacciarelli A, Gibson D. Unusual complication of peripherally inserted central venous catheter placement: the left pericardiophrenic vein. Pediatr Radiol. 2004; 34 180-1. Available from: $\quad$ https://link.springer.com/article/10.1007\%2Fs0024 7-003-1078-3.

5. Choudhry S, Sharma AK, Singh H. Undivided Retromandibular Vein Continuing as External Jugular Vein with Facial Vein Draining into It: An Anatomical Variation. JK Science. 2010 December; 12(4): 203 - 204. Available from: https://www.researchgate. net/publication/50367349 Undivided Retromandibular Vein Continuing As External Jugular Vein With Facial Vein Draining Into It An Anatomical Variation.

6. Standring S. Gray's anatomy. 39th ed. London: Elsevier Churchil Livingstone. 2005. p. 965, 1025.

7. Vollala VR, Pamidi N, Potu B K. Internal thoracic vein draining into the extrapericardial part of the superior vena cava: a case report. Jornal Vascular Brasileiro. 2008; 7(1), 80-3. Available from: https://dx.doi.org/10.1590/\$1677-54492008000100015

8. Ferreira-Arquez $\mathrm{H}$. Variaciones anatómicas en el drenaje venoso del cuello. Rev CES Med. 2016; 30(2): 238-43. Available from: $\quad$ http://revistas.ces.edu.co/index.php/medicina/article/ view/3187/2685

9. Ferreira- Arquez $\mathrm{H}$. Unusual venous drainage of the head and neck. Int J Pharm Bio Sci. 2014 Oct; 5(4): (B) 965 - 70. Available from: http://www.ijpbs.net/cms/php/upload/3710_pdf.pdf
10. Onishi $S$ et al. Venous drainage of the face. J Plast Reconstr Aesthet Surg. 2017;70(4):433-40. Available from: http://www. sciencedirect.com/science/article/pii/S1748681516305514

11. Hamilton, Boyd, Mossman. 4th ed. Heffer Cambridge: 1972. Human Embryology; P-26 1.

12. Williams PL, Warwick R, eds. Gray's Anatomy. 36th Ed. Philadelphia, W B Saunders co.1985:196.

13. Mehra S, Kaul J M, Das S. Unusual venous drainage pattern of face: a case report. J Anat Soc India. 2003; 52: 64-5. Available from: http://medind.nic.in/jae/t03/i1/jaet03i1p64.pdf

14. Singla R K, Singla S, Sachdeva K. Partial duplication of external jugular vein forming a venous ring around supraclavicular nerve: a case report, J Clin Diagn Res. 2011; 5: 8596 Available from: https://pdfs.semanticscholar.org/c8ba/ e3c227a4aa57cbf11b9039b10cf9f7062a14.pdf

15. Ghosal T, Begum S, Roy T, Gupta I. A rare variation of superficial venous drainage pattern of neck. IJARS. 2014;3 (4): 1-3. Available from: http://www.ijars.net/articles/PDF/2015/1-\%20 10764 CE(AJ) F(Sh) PF1(AJ Sh) PFA(AK).pdf

16. Prakash $B B$, Bhagath KP. A rare termination of left common facial vein into left subclavian vein. A case report. Int. J. Morphol. 2007; 25(3):555-6. Available from: http://www.scielo. cl/scielo.php?pid=S0717-95022007000300013\&script=sci_ abstract\&tlng $=p t$

17. Bertha A, Rabi S. Anatomical Variations in Termination of Common Facial Vein. J Clini Res. 2011; 5(1):24-7. Available from: http://www.jcdr.net/articles/pdf/1174/1592 1554 E(C) $F(J) \quad R($ S) $P F(A) P(24-27)$ LowRes.pdf

18. Kopuz C, Yavuz S, Cumhur M, Tetik S, Ilgi S. An unusual coursing of the facial vein. Kaibogaku Zasshi. 1995;70: 20-2. Available from: https://www.ncbi.nlm.nih.gov/pubmed/7785407

19. Peuker E.T, Fischer G, Filler TJ. Correspondence- Facial vein terminating in the superficial temporal vein: a case report. J Anat. 2001; 198: 509-10. Available from: http://onlinelibrary. wiley.com/doi/10.1046/j.1469-7580.2001.19840509.x/pdf

20. Choudhry R, Tuli A, Choudhry S Facial vein terminating in the external jugular vein. An embryological interpretation. Surg Radiol Anat. 1997; 19: 73-7. Available from: https://www.ncbi. nlm.nih.gov/pubmed/9210239

21. Gupta V, Tuli A, Choudhry R, Agarwal S, Mangal A. Facial vein draining into external jugular vein in human: its variations, phylogenetic retention and clinical relevance. Surg Radiol Anat. 2003; 25: 36-41. Available from: https://www.ncbi.nlm.nih.gov/ pubmed/12819948

22. Pai M, Vadgaonkar R, Prabhu L, Shetty P. The different termination patterns of the facial vein-A cadaveric study. Firat Tip Dergisi.2008;13 (1): 32-4 Available from: http://www. firattipdergisi.com/pdf/pdf FTD 455.pdf 
23. Siddaraju KS. Unusual Drainage of Common Facial Vein. Int. J. Chem. and Life Sciences. 2013; 2 (7): 1193-4. Available from: http://www.ijcls.com/index.php/ijcls/article/view/74

24. Pikkieff E. Subcutaneous veins of the neck. Journal of Anatomy. 1937; 72-119. Available from: https://www.ncbi.nlm.nih.gov/ pmc/articles/PMC1252446/

25. Tsikaras P, Paraskevas G, Natsis K. External Jugular Vein. In: Tsikaras P, Paraskevas G, Natsis K. Circulatory System. Volume 2. Thessaloniki: University Studio Press, 2005: 212-5.

26. Williams PL. Gray's Anatomy. 38th ed. Edinburgh: Churchill Livingstone, 1995: 1578-9.

27. Deslaugiers B, Vaysse P, Combes JM, et al. Contribution to the study of the tributaries and the termination of the external jugular vein. Surg Radiol Anat. 1994; 16(2): 173-7. Available from: https://www.ncbi.n/m.nih.gov/pubmed/7940081

28. Schummer W, Schummer C, Bredle D, Fröber R. The anterior jugular venous system: variability and clinical impact. Anesth Analg. 2004; 99(6): 1625-9. Available from: https://www.ncbi. nlm.nih.gov/pubmed/15562044

29. Nayak BS. Surgically important variations of the jugular veins. Clin Anat. 2006; 19(6): 544-6. Available from: https://www. ncbi.nlm.nih.gov/pubmed/16372344

30. Fabian FM, Gesase AP. Anomalous jugular veins system in an adult male cadaver. Ital J Anat Embryol. 2006; 111(4): 215-20. Available from: https://www.ncbi.nlm.nih.gov/ pubmed/17385277

31. Maskey D, Baral P, Kuwar RB, et al. Unusual venous drainage of face: a case report. Nepal Med Coll J. 2006; 8(4): 286-7. Available from: https://www.ncbi.nlm.nih.gov/pubmed/17357652

32. Paraskevas G, Natsis K, loannidis O, Kitsoulis $P$, Anastasopoulos $\mathrm{N}$, Spyridakis I. Multiple variations of the superficial jugular veins: case report and clinical relevance. Acta Medica (Hradec Kralove). 2014;57(1):34-7. Available from: https://www.ncbi. nlm.nih.gov/pubmed/25006662

33. Schwabegger AH, Ninkovic MM, Morigl B, Waldenberger $P$, Brenner E, Wechselberger $G$, Anderl $H$. Internal mammary veins: classification and surgical use in free-tissue transfer. J Reconstr Microsurg. 1997; 13: 17-23. Available from: https://www.ncbi. nlm.nih.gov/pubmed/9120838

34. Loukas M, Tobola MS, Tubbs RS, Louis RG Jr, Karapidis M, Khan I, Spentzouris G, Linganna S, Curry B. The clinical anatomy of the internal thoracic veins. Folia Morphol (Warsz). 2007; 66(1):25-32. Available from: https://www.ncbi.nlm.nih.gov/ pubmed/17533591

35. Romanes GJ. Cunningham's textbook of anatomy.11th ed. Oxford University Press, London, England, 1972: 907.

36. Schwabegger, AH, Bodner G, Rieger $M$, Jaschke WR, Ninkovic MM. Internal mammary vessels as a model for power Doppler imaging of recipient vessels in microsurgery. Plast Reconstr Surg. 1999; 104: 1656-61. Available from: https://www.ncbi.nlm.nih. gov/pubmed/10541165
37. Clark III CP, Rohrich RJ, Copit S, Pittman CE, Robinson J. An anatomic study of the internal mammary veins: clinical implications for free-tissue-transfer breast reconstruction. Plast Reconstr Surg. 1997; 99: 400-4. Available from: https://www. ncbi.nlm.nih.gov/pubmed/9030147

38. Henriquez-Pino JA, Gomes WJ, Prates JC, Buffolo E. Surgical anatomy of the internal thoracic artery. Ann Thorac Surg. 1997; 64: 1041-5. Available from: http://www.annalsthoracicsurgery. org/article/S0003-4975(97)00720-0/pdf

39. De Jesus RA, Acland RD. Anatomic study of the collateral blood supply of the sternum. Ann Thorac Surg. 1995; 59: 163-8. Available from: https://www.ncbi.nlm.nih.gov/ pubmed/7818316

40. Pietrasik K, Bakon L, Zdunek P, Wojda-Gradowska U, Dobosz P, Kolesnik A. Clinical anatomy of internal thoracic artery branches. Clin Anat. 1999; 12: 307-14. Available from: https://www.ncbi. nlm.nih.gov/pubmed/10462728

41. Bauer EP, Bino MC, von Segesser LK, Laske A, Turina MI. Internal mammary artery anomalies. Thorac Cardiovasc Surg. 1990; 38: 312-15. Available from: https://www.thieme-connect.com/DOI/ DOI?10.1055/s-2007-1014041

42. Canver CC, Ricotta JJ, Bhayana JN, Fiedler RC, Mentzer RM. Use of duplex imaging to assess the suitability of the internal mammary for coronary artery surgery. J Vasc Surg. 1991; 13: 294-301. Available from: https://www.ncbi.nlm.nih.gov/ pubmed/1990169

43. Sons HJ, Marx R, Godehardt E, Losse B, Kunert J, Bircks W. Duplex sonography of the internal thoracic artery: preoperative assessment. J Thorac Cardiovasc Surg. 1994; 108: 549-55. Available from: https://www.ncbi.nlm.nih.gov/ pubmed/8078348

44. Bruneton JN, Dalfin FY, Caramella E, Roux P, Hery M. Value of ultrasound in localizing the internal mammary vessels. Eur J Radiol. 1986; 6: 142-4. Available from: https://www.ncbi.nlm. nih.gov/pubmed/3522233

45. Glassberg RM, Sussman SK, Glickstein MF. CT anatomy of the internal mammary vessels: importance in planning percutaneous transthoracic procedures. Am J Roentgenol. 1990; 155: 397-400. Available from: https://www.ncbi.nlm.nih. gov/pubmed/2115273

46. Kuzo RS, Ben-Ami TE, Yousefzadeh DK, Ramirez JG. Internal mammary compartment window to the mediastinum. Radiology. 1995;195: 187-92. Available from: https://www.ncbi. nlm.nih.gov/pubmed/7892466

47. Scatarige JC, Hamper UM, Sheth S, Allen III HA. Parasternal sonography of the internal mammary vessels: technique, normal anatomy, and lymphadenopathy. Radiology. 1989; 172: 453-57. Available from: https://www.ncbi.nlm.nih.gov/ pubmed/2664869

48. Clemente CD. Gray's anatomy of the human body. 13th Ed. Lea \& Febiger, Philadelphia, PA, 1985: 829. 
49. Vaseghi M, Cesario DA, Ji S, Shannon KM, Wiener I, Boyle NG, Fonarow GC, Valderrábano M, Shivkumar K. Beyond coronary sinus angiography: the value of coronary arteriography and identification of the pericardiophrenic vein during left ventricular lead placement. Pacing Clin Electrophysiol. 2005;28 (3):185-90. Available from: https://www.ncbi.nlm.nih.gov/ pubmed/15733176

50. Kogan AD, Malek M. Blind cannulation of the left pericardiophrenic vein: An unusual cause of diaphragmatic pacing. Pacing Clin Electrophysiol. 1993; 16:356-9. Available from: https://www.ncbi.n/m.nih.gov/pubmed/7680467

51. Van Haeften TW, van PampusEC, BootH, etal. Cardiactamponade from misplaced central venous line in pericardiophrenic vein. Arch Int Med 148:1649-50. Available from: https://www.ncbi. nlm.nih.gov/pubmed/3382311

52. McLellan BA, Jerman MR, French WJ, et al. Inadvertent SwanGanz catheter placement in the left pericardiophrenic vein. Cathet Cardiovasc Diagn. 1989; 16:173-5. Available from: http:// onlinelibrary.wiley.com/doi/10.1002/ccd.1810160307/abstract

53. Meyer CA, White CS, Sherman KE. Diseases of the hepatopulmonary axis. Radiographics. 2000; 20:68798. Available from: http://pubs.rsna.org/doi/full/10.1148/ radiographics.20.3.g00ma17687

54. Widrich WC, Srinivasa M, Semine MC, et al. Collateral pathways of left gastric vein in portal hypertension. Am J Roentgenol. 1984; 14:375-82. Available from: https://www.ncbi.nlm.nih. gov/pubmed/6607610

55. Ferozkhan $P$, Ramdas $S$, Balsurkar $S$, Hashmi R. Variation in the termination of common facial vein- a case report. IJRTSAT. 2015; 15(1): 13-15

56. Abeysekara AM, Siriwardana HP, Prabaharan B, Tiwari A, adipolagedara $\mathrm{N}$, Jacob S: Common facial vein: an alternative patch material in carotid angioplasty. ANZ.J. Surg. 2008; 78: 185-8. Available from: https://www.ncbi.nlm.nih.gov/ pubmed/18269485

57. Sabharwal P, Mukherjee D: Autogenous common facial vein or external jugular vein patch for carotid endarterectomy. Cardiovasc. Surg. 1998; 6: 594-7. Available from: https://www. ncbi.nlm.nih.gov/pubmed/10395262

58. Bilateral supernumerary sternocleidomastoid heads with clinical and surgical implications. Journal of Chemical and Pharmaceutical Research. 2016, 8(5):527-37. Available from: http://www.jocpr. com/articles/bilateral-supernumerary-sternocleidomastoidheads-with-clinical-and-surgical-implications.pdf

59. Muscular variation in the neck region with narrowing of the minor and major supraclavicular fossa. International Archives Of Medicine, 2017, 10, DOI: https://doi.org/10.3823/2478. Available from: http://imedicalsociety.org/ojs/index.php/iam/ article/view/2328
60. Multi Headed Sternocleidomastoid Muscle: An Anatomical Study. Int J Pharma Bio Sci. 2018 january; 9(1): (b) 249-56. DOI: http://dx.doi.org/10.22376/ijpbs.2018.9.1.b249-256. Available from: http://www.ijpbs.net/abstract.php?article=6339

61. Rott G, Boecker F. Port Placement via the Anterior Jugular Venous System: Case Report, Anatomic Considerations, and Literature Review. Case Reports in Radiology Volume 2017, Article ID 2790290, https://doi.org/10.1155/2017/2790290 Available from: https://www.hindawi.com/journals/crira/2017/2790290/

62. Lalwani P, Aggarwal S, Uppal R, Somchandra. "A case of malpositioned catheter via supraclavicular approach for subclavian vein cannulation: a rare technique revisited," Journal of Anaesthesiology Clinical Pharmacology. 2016; (32) 1: 120 -

2. Available from: https://www.ncbi.n/m.nih.gov/pmc/articles/ PMC4784196/

63. Jung TE, Jee D. "Misplaced central venous catheter in the jugular venous arch exposed during dissection before sternotomy," Journal of Clinical Anesthesia. 2008; 20(7): 542-5. Available from: https://www.ncbi.nlm.nih.gov/pubmed/19019666

64. Chasen $\mathrm{MH}$, Charnsangavej $\mathrm{C}$. "Venous chest anatomy: clinical implications," European Journal of Radiology. 1998; (27):2-14. Available from: http://www.sciencedirect.com/science/article/ pii/S0720048X97001472

65. Premavathy D, Seppan P. "Anatomical variation in the anterior jugular veins and its clinical implications-a case report," Journal of the Anatomical Society of India. 2015; (64) supplement 1: S40-S43. Available from: https://www.researchgate. net/publication/281397459 Anatomical variation in the anterior jugular veins and its clinical implications - A case_report

66. Schummer W, Schummer C, Bredle D, Fröber R, "The anterior jugular venous system: variability and clinical impact," Anesthesia and Analgesia. 2004; (99) 6: 1625-29. Available from: https:// www.ncbi.nlm.nih.gov/pubmed/15562044

Publish in International Archives of Medicine

International Archives of Medicine is an open access journal publishing articles encompassing all aspects of medical science and clinical practice. IAM is considered a megajournal with independent sections on all areas of medicine. IAM is a really international journal with authors and board members from all around the world. The journal is widely indexed and classified Q2 in category Medicine. 